\title{
Influence of A-21T and C-262T genetic polymorphisms at the promoter region of the catalase $(C A T)$ on gene expression
}

\author{
Khyber Saify $^{1} \cdot$ Iraj Saadat $^{1} \cdot$ Mostafa Saadat $^{1}$
}

Received: 9 April 2016/Accepted: 14 May 2016/Published online: 25 May 2016

(C) The Japanese Society for Hygiene 2016

\begin{abstract}
Objective Catalase (CAT, OMIM: 115500) is one of the major antioxidant enzymes, which plays an important role in the clearance of reactive oxygen species. Three genetic polymorphisms of A-21T (rs7943316), C-262T (rs1001179), and C-844T (rs769214) in the promoter region of the CAT have been reported. It has been suggested that these polymorphisms may alter the recognition sites of transcriptional factors, therefore it might be concluded that these polymorphisms may alter the expression levels of the gene. The aim of the present study is to evaluate the associations between these genetic variations and the CAT mRNA levels in human peripheral blood cells. Methods The present study consisted of 47 healthy students of Shiraz University (south-west Iran). Genotypes of the $C A T$ polymorphisms were determined by PCR based method. The quantitative $C A T$ mRNA expression levels were investigated using quantitative real-time PCR.

Results Analysis of variance revealed significant differences between the study genotypes (For A-21T polymorphism: $F=7.45 ; d f=2,44 ; P=0.002$; For $\mathrm{C}-262 \mathrm{~T}$ polymorphism: $F=15.17 ; d f=2,44 ; P<0.001)$. The studied polymorphisms showed linkage disequilibrium $\left(D^{\prime}=1.0, \quad r^{2}=0.1813, \chi^{2}=17.03, \quad P<0.0001\right)$. The mRNA levels of CAT in the AC/TT, TC/TC, TC/TT, and
\end{abstract}

Mostafa Saadat

saadat@shirazu.ac.ir; msaadat41@yahoo.com

Khyber Saify

khaibar.saify@yahoo.com

Iraj Saadat

isaadat@shirazu.ac.ir

1 Department of Biology, College of Sciences, Shiraz University, Shiraz 71467-13565, Iran
TC/TC diplotypes significantly were higher than the mRNA levels in AC/AC diplotype. There was a significant difference between the study genotypes $(F=9.24 ; d f=5$, 41; $P<0.001)$. The TC/TC and TT/TT diplotypes showed about 2 and 4 folds CAT mRNA levels compared with the AC/AC diplotype.

Conclusions The present findings indicated that these polymorphisms were significantly associated with the gene expression.

Keywords mRNA level $\cdot$ Polymorphism $\cdot C A T$

\section{Introduction}

Catalase (EC 1.11.1.6, CAT, OMIM: 115500) is a ubiquitous enzyme found in all organisms. It catalyzes the decomposition of hydrogen peroxide to oxygen and water; therefore it is a major cytoplasmic antioxidant enzyme [1]. Several genetic polymorphisms in the CAT have been reported in human populations (http://www.ncbi.nlm.nih. gov/projects/SNP/snp_ref.cgi?geneId=847). Three genetic polymorphisms have been reported in the promoter region of the CAT named A-21T (rs7943316), C-262T (rs1001179) and C-844T (rs769214) [2-4]. Previous studies have shown that $C A T$ polymorphisms were associated with the risks of several multifactorial diseases [4-13].

It has been suggested that these regions contain numbers of transcription factor binding sites [4, 14]. Associations between two genetic polymorphisms at promoter region of the CAT (C-262T and C-844T) and the promoter activity of CAT have been reported [2, 15]. Functional studies using the CAT promoter activity in several human cell lines (HepG2 and K562) transfected with luciferase constructs, demonstrated that the $-262 \mathrm{~T}$ allele increased the activity of 
the $C A T$ promoter activity by approximately 2 -fold [2]. Considering that there is no study investigating the influence of the A-21T polymorphism on expression of $C A T$ and no in vivo study on the relationship between these polymorphisms and promoter activity of the CAT, the present study was carried out. The aim of the present study is to evaluate the associations between the A-21T and $\mathrm{C}-262 \mathrm{~T}$ polymorphisms and the CAT mRNA levels in human normal peripheral blood cells.

\section{Materials and methods}

The present study consisted of 47 (18 females, 29 males) healthy students of Shiraz University (south-west Iran) between the ages of 20 and 35 years (mean \pm SD $25.3 \pm 3.3$ ). Very recently the alterations of the CAT mRNA levels in SH-SY5Y human cells exposed to methadone and morphine were reported [16, 17], indicating that expression of the CAT may be induced by some drugs and environmental factors. Therefore, the participants had no history of smoking, drug abuse, or drinking alcohol, were not on medication, and had no history of diagnosed several oxidative stress associated disease such as cancers, cardiovascular disease, diabetes, cataract, schizophrenia, bipolar disorder, and epilepsy.

Considering that Iranian population is a heterogeneous population [18-21], we select the participants from healthy students of Shiraz University. The participants were Persian (Caucasians) Muslims living in Shiraz (Fars province, south-west Iran). Informed consent was obtained from each volunteer before the study. This study was approved by the Shiraz University ethics committee.

Sample size calculation was undertaken using the QUANTO (http://biostats.usc.edu/software) software. To detect a real difference in the mRNA levels between the genotypes of the study polymorphisms with a power of $0.80, \alpha=0.05, R_{\mathrm{g}}^{2}$ (marginal proportion of variance in the $C A T$ mRNA levels explain by the polymorphisms) $=0.25$, a minimum sample of 27 would be necessary. Therefore, the present study is more than sufficiently powered with an $N=47$ subjects to detect a large effect in mRNA levels between the different genotypes.

Genotyping for the CAT A-21T and C-262T polymorphisms were carried out using PCR based method, as described previously $[3,5]$.

Total RNA was isolated from peripheral blood cells by RNX-Plus kit (CinnaGene, Iran) following the manufacturer's instructions. RNA samples were used for cDNA synthesis using the PrimeScript RT reagent Kit (Takara, Japan). Relative abundance of the CAT mRNA level was assessed using quantitative real-time PCR using a Rotorgene 6000 real-time PCR system (Corbett Life Science) by
SYBR Green Premix Ex Taq II Kit (Takara, Japan), as described previously [16]. The SYBR green I fluorescence intensity was acquired at the end of the extension step of each cycle. Relative differences in gene expression were expressed using cycle threshold $(C t)$ values. $\Delta \mathrm{Ct}$ means difference of $C t$ between $T B P$ and $C A T$. The relative $C A T$ expression versus the expression of $T B P$ for each individual was determined using $2^{-\Delta C t}$ [22]. All the assays were undertaken under identical conditions and carried out in duplicate.

The software SNPAlyze(TM) ver. 6 Standard (Dynacom Co, Ltd. Kanagawa, Japan) was used to evaluate the status of pair wise linkage disequilibrium for the studied polymorphisms of $C A T$ at -21 and -262 sites.

Chi-square test was performed for the polymorphism to determine if the subjects demonstrated Hardy-Weinberg equilibrium. The CAT expression levels were expressed as mean \pm SE. Influence of the genotypes and/or dioplotypes on the CAT mRNA levels was investigated using Analysis of Variance (ANOVA) followed by Bonferroni post hoc test. Pearson correlation coefficients between the mRNA levels and number of variant alleles were calculated. Statistical analysis was performed using the Statistical Package for Social Sciences (SPSS Inc., Chicago, IL, USA; version 11.5). A probability of $P<0.05$ was considered statistically significant.

\section{Results and discussion}

Figure 1 shows the CAT mRNA levels in the genotypes of both study polymorphisms. For the A-21T polymorphism, in our samples, 19, 21 and 7 participants have the AA, AT and TT genotypes, respectively. The genotypes in the study group were in accordance with the Hardy-Weinberg equilibrium $\left(\chi^{2}=0.09, d f=1, P=0.762\right)$. The mean (SE) of the $C A T$ relative expression levels versus the $T B P$ expression in the AA, AT and TT genotypes were estimated to 8.06 (1.09), 13.41 (1.05) and 16.96 (1.45), respectively (Fig. 1a). There is a significant positive correlation between number of the $\mathrm{T}$ allele and the $C A \mathrm{~T}$ mRNA levels $(r=0.495, d f=45, P<0.001)$. Analysis of variance revealed a significant difference between the study genotypes $(F=7.45 ; d f=2,44 ; P=0.002)$.

For the C-262T polymorphism, in our samples 27,18 and 2 participants have the CC, CT and TT genotypes, respectively. The genotypes in the study group were in accordance with the Hardy-Weinberg equilibrium $\left(\chi^{2}=0.21, d f=1, P=0.640\right)$. The mean $( \pm \mathrm{SE})$ of the $C A T$ relative expression levels versus the TBP expression in the CC, CT and TT genotypes were estimated to 12.33 (0.87), 14.73 (1.03) and 31.22 (7.63), respectively (Fig. 1b). Statistical analysis revealed a significant 


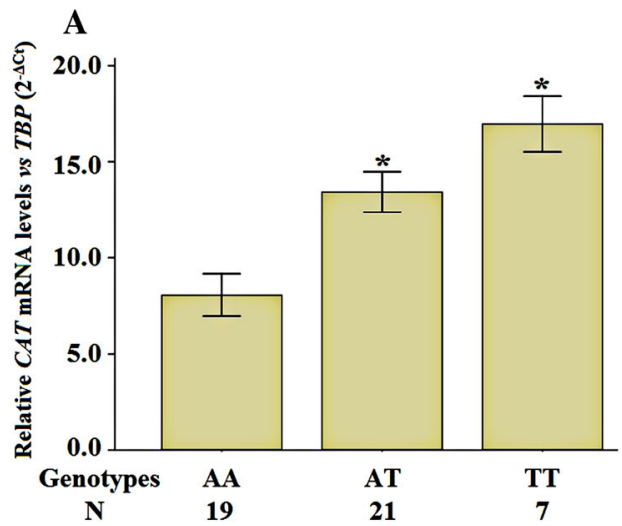

Fig. 1 The $C A T$ mRNA levels versus the $T B P$ levels in the genotypes of the A-21T (a) and C-262T (b) genetic polymorphism at promoter region of the $C A T$ gene. $* P<0.05$ all values compared with reference genotypes (the AA and CC genotypes for the A-21T and

difference between the study genotypes $(F=15.17$; $d f=2,44 ; P<0.001)$. There is a significant positive correlation between number of the $\mathrm{T}$ allele and the CAT mRNA levels $(r=0.501, d f=45, P<0.001)$. This finding confirmed previous in vitro study [2]. Other authors reported that the association between $\mathrm{C}-262 \mathrm{~T}$ polymorphism and enzyme activity of CAT [23-25]. They have been shown that the CC genotype had higher CAT activity compared with the CT or TT genotypes [23, 24]. In one study, no association between the C-262T polymorphism and enzyme activity of CAT was observed [25]. Apart from genetic polymorphisms, a number of environmental factors have significant influence on the CAT activity [4]. It should be noted that in some of these studies, the authors study on breast cancer patients or coal miners [5, 23, 24]. It is very probable that on the CAT enzyme activity, significant interaction exist between genetic polymorphisms and some of environmental factors.

The closed physical proximity of the study polymorphisms should place them in linkage disequilibrium. Based on the complete dataset the study polymorphisms showed a linkage disequilibrium $\left(D^{\prime}=1.0, r^{2}=0.1813, \chi^{2}=17.03\right.$, $P<0.0001$ ). The haplotypes $-21 \mathrm{~T} /-262 \mathrm{C}$ (TC), $-21 \mathrm{~A} /-262 \mathrm{C}$ (AC), and -21T/-262T (TT) have frequencies of 0.3936 , 0.3723 , and 0.2340 , respectively. Considering the high level of the linkage disequilibrium between the two polymorphic sites, we did not observe the -21A/-262T haplotype among our subjects. Figure 2 shows the CAT mRNA levels in different diplotypes. Analysis of variance revealed a significant difference between the study dioplotype $(F=9.24 ; d f=5$, $41 ; P<0.001)$. The mRNA levels of CAT in the AC/TT, TC/TC, TC/TT, TC/TC, and TT/TT diplotypes significantly were higher than the mRNA levels in AC/AC diplotype. The diplotypes TC/TC and TT/TT showed about 2 and 4 folds $C A T$ mRNA levels compared with the AC/AC diplotype,

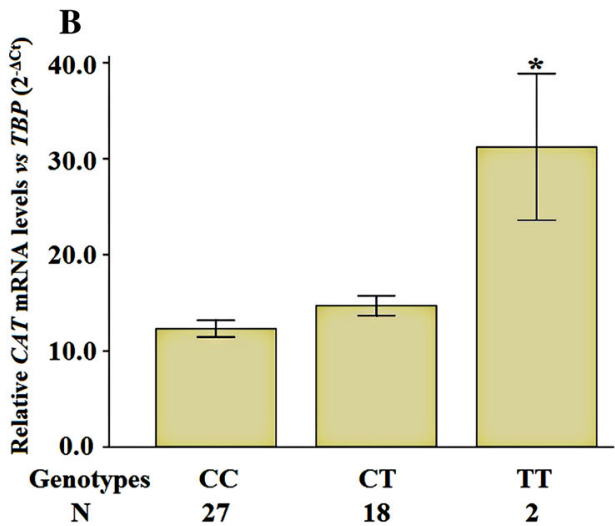

C-262T polymorphism, respectively) using Bonferroni post hoc test. Data were shown as mean \pm SE. $N$ shows the number of participants with each genotype

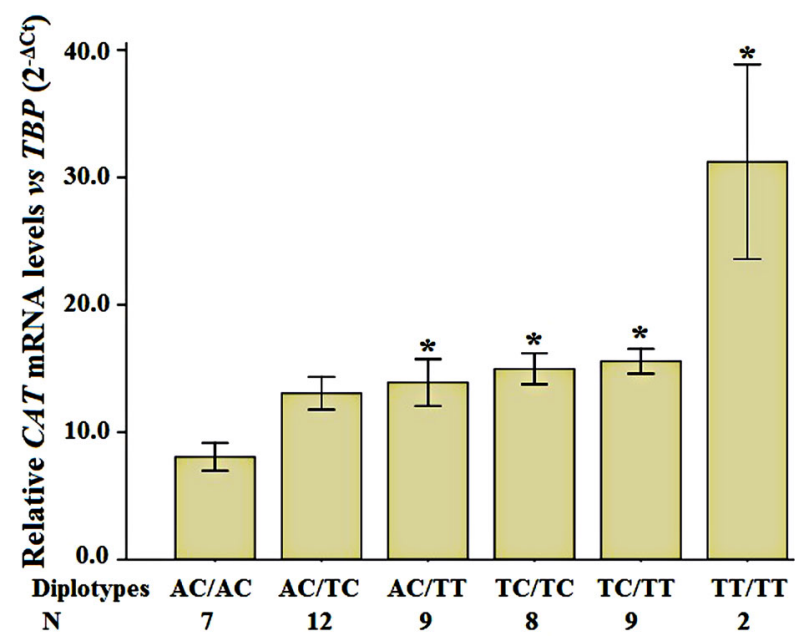

Fig. 2 The $C A T$ mRNA levels versus the $T B P$ levels in the diplotypes of the A-21T and $\mathrm{C}-262 \mathrm{~T}$ genetic polymorphism at promoter region of the $C A T$ gene. $* P<0.05$ all values compared with reference dioplotype (AC/AC) using Bonferroni post hoc test. Data were shown as mean \pm SE. $N$ shows the number of participants with each haplotype

respectively. There was significant positive association between the number of variant substitutions (at both A-21T and C-262T polymorphic sites) and the CAT mRNA levels $(r=0.598, d f=45, P<0.001)$.

It has been shown that oxidative stress significantly associated with several multifactorial traits [26-28]. Catalase catalyzes the decomposition of hydrogen peroxide to oxygen and water it is potentially important in etiology of several complex diseases. Considering that the A-21T and $\mathrm{C}-262 \mathrm{~T}$ polymorphisms in the promoter region of $C A T$, significantly associated with the activity of promoter of the $C A T$; subsequently it may alter the risk of oxidative stress related disorders. 
Recent studies indicated that several environmental factors such as some drugs [16, 17], electromagnetic fields [29], and MTBE (methyl-tertiary butyl ether, a gasoline additive) [30], may alter the expression levels of some antioxidant genes. On the other hand, epidemiological studies have been indicated that high consumption of cruciferous vegetables would reduce cancer risk [3133]. It has been reported that erythrocyte catalase activity is significantly associated with the C-262T polymorphism. Higher activity was reported for the CC genotype [23]. However, this is not consistent with our present finding. It should be noted that previously it was reported that erythrocyte catalase activity is significantly associated with total fruit and vegetables consumptions [23]. In the present study we did not ask the participants about their environmental factors and life style such as dietary consumption of cruciferous vegetables. Taken together, simultaneous study the influence of the CAT A-21T and C-262T polymorphisms and environmental factors on the CAT mRNA level should be further researched. Finally it should be noted that in the present study we used semiquantitative RT-PCR to compare the relative CAT expression levels. Given that it has been reported that the small differences (less than 1.5 times) is conceived to be beyond the limitation of reproducibility [34], and we did not confirm our mRNA levels data with the CAT protein levels, the present results need to be interpreted with care. Simultaneous study of the influence of three genetic polymorphisms at promoter region of the $C A T$ on its mRNA levels and its enzyme activity with respect to environmental factors should be further researched using a large sample size.

Acknowledgments The authors are indebted to the participants for their close cooperation. This study was supported by Shiraz University (Grant Number: 93GRD3M1741).

\section{Compliance with ethical standards}

Conflict of interest The authors declare they have no conflict of interest.

\section{References}

1. Ogata M. Acatalasemia. Hum Genet. 1991;86:331-40.

2. Forsberg L, Lyrenäs L, de Faire U, Morgenstern R. A common functional C-T substitution polymorphism in the promoter region of the human catalase gene influences transcription factor binding, reporter gene transcription and is correlated to blood catalase levels. Free Radic Biol Med. 2001;30:500-5.

3. Lourdhu Mary A, Nithya K, Isabel W, Angeline T. Prevalence of catalase $(-21 \mathrm{~A} / \mathrm{T})$ gene variant in south Indian (Tamil) population. Biomed Res Int. 2014;2014:894237.

4. Kodydková J, Vávrová L, Kocík M, Žák A. Human catalase, its polymorphisms, regulation and changes of its activity in different diseases. Folia Biol (Praha). 2014;60:153-67.
5. Saadat M, Saadat S. Genetic polymorphism of CAT C-262 T and susceptibility to breast cancer, a case-control study and metaanalysis of the literatures. Pathol Oncol Res. 2015;21:433-7.

6. Ebrahimpour S, Saadat I. Association of CAT C-262T and SOD1 A251G single nucleotide polymorphisms susceptible to gastric cancer. Mol Biol Res Commun. 2015;4:223-9.

7. Zarei N, Saadat I, Farvardin-Jahromi M. The relationship between NQO1 C609T and CAT C-262T genetic polymorphisms and the risk of age-related cataracts. Mol Biol Res Commun. 2015;4:143-9.

8. Hu J, Feng F, Zhu S, Sun L, Li G, Jiang N, Shang Z, Niu Y. Catalase C-262T polymorphism and risk of prostate cancer: evidence from meta-analysis. Gene. 2015;558:265-70.

9. Shen Y, Li D, Tian P, Shen K, Zhu J, Feng M, Wan C, Yang T, Chen L, Wen F. The catalase C-262T gene polymorphism and cancer risk: a systematic review and meta-analysis. Med (Baltim). 2015;94:e679.

10. Saygi S, Erol İ, Alehan F, Yalçın YY, Kubat G, Ataç FB. Superoxide dismutase and catalase genotypes in pediatric migraine patients. J Child Neurol. 2015;30:1586-90.

11. Góth L, Vitai M. Polymorphism of $5^{\prime}$ of the catalase gene in Hungarian acatalasemia and hypocatalasemia. Electrophoresis. 1997; 18:1105-8.

12. Wang SL, Yu LG, Liu RP, Zhu WZ, Gao WM, Xue LP, Jiang X, Zhang YH, Yi D, Chen D, Zhang YH. Gene-gene interaction of GJB2, SOD2, and CAT on occupational noise-induced hearing loss in Chinese Han population. Biomed Environ Sci. 2014;27:965-8.

13. Vialykh EK, Solidolova MA, Bushueva O, Bulgakova IV, Polonikov AV. Catalase gene polymorphism is associated with increased risk of cerebral stroke in hypertensive patients. $\mathrm{Zh}$ Nevrol Psikhiatr Im S S Korsakova. 2012;112:3-7 (in Russian).

14. Saify K. Genetic polymorphisms in the promoter region of catalase gene, creates a new potential PAX-6 and STAT4 response element. Mol Biol Res Commun. 2016;5:97-100.

15. Hebert-Schuster M, Cottart CH, Laguillier-Morizot C, RaynaudSimon A, Golmard JL, Cynober L, Beaudeux JL, Fabre EE, Nivet-Antoine V. Catalase rs769214 SNP in elderly malnutrition and during renutrition: is glucagon to blame? Free Radic Biol Med. 2011;51:1583-8.

16. Saify K, Saadat M. Expression patterns of antioxidant genes in human SH-SY5Y cells after treatment with methadone. Psychiatry Res. 2015;230:116-9.

17. Saify K, Saadat I, Saadat M. Down-regulation of antioxidant genes in human SH-SY5Y cells after treatment with morphine. Life Sci. 2015;144:26-9.

18. Rafiee L, Saadat I, Saadat M. Glutathione S-transferase genetic polymorphisms (GSTM1, GSTT1 and GSTO2) in three Iranian populations. Mol Biol Rep. 2010;37:155-8.

19. Saadat M. Distribution of $A C E$ insertion/deletion (I/D) polymorphism in Iranian populations. Mol Biol Res Commun. 2015;4:63-6.

20. Saadat M, Mousavi-Kazerooni, Fallahzadeh-Abarghooei L. Distribution of genetic polymorphism of CAT C-262T in three Iranian populations. Turk J Biochem. 2015;40:386-9.

21. Fallahzadeh-Abarghooei L, Zahedi T, Mirabedi F, Saadat M. Alleleic prevalence of intron 3 insertion/deletion genetic polymorphism of DNA double-strand break repair gene XRCC4 in four Iranian populations. Egypt $\mathrm{J}$ Med Hum Genet. 2015;16:215-8.

22. Schmittgen TD, Livak KJ. Analyzing real-time PCR data by the comparative $\mathrm{C}_{\mathrm{T}}$ method. Nat Protoc. 2008;3:1101-8.

23. Ahn J, Nowell S, McCann SE, Yu J, Carter L, Lang NP, Kadlubar FF, Ratnasinghe LD, Ambrosone CB. Associations between catalase phenotype and genotype: modification by epidemiologic factors. Cancer Epidemiol Biomark Prev. 2006;15:1217-22. 
24. Nadif R, Mintz M, Jedlicka A, Bertrand JP, Kleeberger SR, Kauffmann F. Association of CAT polymorphisms with catalase activity and exposure to environmental oxidative stimuli. Free Radic Res. 2005;39(12):1345-50.

25. Mak JCW, Ho SP, Yu WC, Choo KL, Chu CM, Yew WW, Lam WK, Chan-Yeung MW. Polymorphisms and functional activity in superoxide dismutase and catalase genes in smokers with COPD. Eur Respir J. 2007;30:684-90.

26. Smaga I, Niedzielska E, Gawlik M, Moniczewski A, Krzek J, Przegaliński E, Pera J, Filip M. Oxidative stress as an etiological factor and a potential treatment target of psychiatric disorders. Part 2. Depression, anxiety, schizophrenia and autism. Pharmacol Rep. 2015;67:569-80.

27. Beebe DC, Holekamp NM, Shui YB. Oxidative damage and the prevention of age-related cataracts. Ophthalmic Res. 2010;44:155-65.

28. He F, Zuo L. Redox roles of reactive oxygen species in cardiovascular diseases. Int J Mol Sci. 2015;16:27770-80.

29. Mahmoudinasab H, Sanie-Jahromi F, Saadat M. Effects of extremely low-frequency electromagnetic field on expression levels of some antioxidant genes in MCF-7 cells. Mol Biol Res Commun. 2016;5:77-85.

30. Badr AA, Saadat I, Saadat M. Study of liver function and expression of some detoxification genes in the male rats exposed to methyl-tertiary butyl ether. Egypt J Med Hum Genet. 2016. doi: 10.1016/j.2ejmhg.2015.10.002.

31. Higdon JV, Delage B, Williams DE, Dashwood RH. Cruciferous vegetables and human cancer risk: epidemiologic evidence and mechanistic basis. Pharmacol Res. 2007;55:224-36.

32. Chan R, Lok K, Woo J. Prostate cancer and vegetable consumption. Mol Nutr Food Res. 2009;53:201-16.

33. Tang L, Zirpoli GR, Guru K, Moysich KB, Zhang Y, Ambrosone $\mathrm{CB}$, McCann SE. Consumption of raw cruciferous vegetables is inversely associated with bladder cancer risk. Cancer Epidemiol Biomark Prev. 2008;17:938-44.

34. Dallas PB, Gottardo NG, Firth MJ, Beesley AH, Hoffmann K, Terry PA, Freitas JR, Boag JM, Cummings AJ, Kees UR. Gene expression levels assessed by oligonucleotide microarray analysis and quantitative real-time RT-PCR-how well do they correlate? BMC Genom. 2005;6:59. 